Article

\title{
Is Self-Reported Physical Fitness Useful for Estimating Fitness Levels in Children and Adolescents? A Reliability and Validity Study
}

\author{
Augusto César Ferreira De Moraes ${ }^{1,2,+} \mathbb{0}$, Regina Célia Vilanova-Campelo $2,3,+[$, \\ Francisco Leonardo Torres-Leal ${ }^{2}$ and Heráclito Barbosa Carvalho ${ }^{1, *}$ \\ 1 Department of Epidemiology; School of Public Health, University de São Paulo, 01246-904 São Paulo, Brazil; \\ augusto.moraes@fm.usp.br \\ 2 YCARE (Youth/Child cArdiovascular Risk and Environmental) Research Group, Faculdade de Medicina, \\ Universidade de São Paulo, 01246-903 São Paulo, Brazil; regina.vilanova-campelo@usp.br (R.C.V.-C.); \\ torresleal@ufpi.edu.br (F.L.T.-L.) \\ 3 DOMEN (Metabolic Diseases, Exercise and Nutrition) Research Group, Department of Biophysical and \\ Physiology, Federal University of Piaui, 64049-550 Teresina, Brazil \\ * Correspondence: heracc@usp.br \\ + Equally contributed first author.
}

Received: 4 November 2018; Accepted: 13 June 2019; Published: 18 June 2019

\begin{abstract}
Background and objective: The assessment of physical fitness has become a necessary issue in epidemiological studies, since a reduction in fitness is directly associated with early mortality. Therefore, the development of simple, accurate, and inexpensive methods is necessary to measure physical fitness. This study aimed to determine the reliability and validity of the criteria and constructs of the International Fitness Scale (IFIS), Portuguese version, in Brazilian pediatric populations. Methods: A total of 190 children aged 3-10 years and 110 adolescents aged 11-17 years were enrolled in an observational study of reliability and validity. For reliability, the participants completed a questionnaire twice (with an interval of 15 days). To test the criterion validity, we analyzed the agreement between the questionnaire and physical tests (20-m shuttle run test, handgrip strength, standing long jump tests, $4 \times 10$-m shuttle run test, and back-saver sit and reach test), and the construct validity was estimated by agreement between the questionnaire and high blood pressure. The reliability was analyzed by kappa coefficients. The agreement between the testing and retesting of the questionnaire was evaluated by kappa coefficients. We applied a $2 \times 2$ table to estimate the specificity, sensitivity, and accuracy of the questionnaire. Results: The mean age of the children was 6.7 years $(n=190)$, and for the adolescents it was 14.6 years $(n=110)$. The questionnaire reliability showed an almost perfect score ( $k \geq 0.93$ in children and $k \geq 0.88$ in adolescents). The questionnaire showed moderate criterion validity ( $\kappa \geq 0.40$ in children and adolescents) as well as moderate construct validity $(\kappa \geq 0.40)$ in the components of general conditioning, cardiorespiratory capacity, muscular strength, and speed/agility in children and in the components of cardiorespiratory capacity, muscle strength, and speed/agility in adolescents. The questionnaire was a sensitive method for measuring physical fitness. Conclusions: The Portuguese version of the IFIS is a reliable and valid method for measuring physical fitness in pediatric populations.
\end{abstract}

Keywords: physical fitness; questionnaire; reliability; validity; children; adolescents; self-reported

\section{Introduction}

Physical fitness integrates the measures of most body functions, such as skeletomuscular and cardiorespiratory functions, involved in the performance of daily physical activity and/or physical exercise [1], which is the reason why physical fitness is considered an important health marker [2]. 
Physical fitness is defined as a state of well-being, which refers to the ability to perform daily tasks, sports, or occupations without undue fatigue [3]. Furthermore, it is recognized as a set of attributes that are either health- or skill-related [4]. The regular practice of physical exercise contributes to the improvement of physical fitness [5]. Studies have indicated that physical inactivity [6] and reduced physical fitness are associated with an increasing number of health problems, mainly obesity, cardiovascular diseases, musculoskeletal health problems, and mental health issues [7,8].

In addition, longitudinal cohort data have indicated that low levels of physical fitness in late adolescence are associated with an increased risk of all-cause mortality in adulthood [9]. On the other hand, high levels of physical fitness in childhood and adolescence are related to more favorable health outcomes $[3,10]$. These studies demonstrated that physical fitness screening is necessary in health-related educational follow-ups and in epidemiological studies [11].

Fitness tests are usually assessed in laboratories or fields: However, in the school context, the estimated time to perform a physical fitness assessment in 20 children/adolescents is approximately $2 \mathrm{~h}$ and $30 \mathrm{~min}$, i.e., three 55-minute physical education classes [10]. Therefore, this type of evaluation remains difficult to perform in the school environment and/or in epidemiological studies due to limited time, space requirements, and material availability [12]. As an alternative, the use of a questionnaire can be considered in the measurement of physical fitness [12].

Ortega et al. proposed a subjective (self-reported) method called the International Fitness Scale (IFIS) to measure physical fitness levels in epidemiological surveys when this evaluation cannot be performed due to time and budget constraints [12]. This scale is available in nine different languages and evaluates general physical, cardiorespiratory, and muscular fitness as well as agility and flexibility [12]. The reliability and validity of the questionnaire in children, adolescents, adults, and other populations have been studied [13-15], but before accepting it for global use, it is necessary to validate it in different populations and age groups [12].

Studies have been conducted in older children [15]: However, it is unknown whether the IFIS is a reliable and valid instrument in 3-8-year-olds. To validate a Portuguese version of the IFIS would be useful given that it is the sixth most spoken language (native speakers) in the world. Beyond language translation, cultural adaptation of this kind of tool for different countries needs to be studied. To the best of our knowledge, this questionnaire has been previously used in South American samples [12,14,15], without its validity having been studied in Brazilians, so this study is of special interest in interpreting previous findings in these countries and advising of its usefulness in future studies. Examining physical fitness from an early age may contribute to the development of strategies to prevent the reduction of physical fitness throughout life [16]. Furthermore, no reliability and validation study of this questionnaire with a field test and blood pressure (BP) has been identified in the pediatric population of South America, specifically in Brazilians. Hence, the purpose of the present study was to determine the reliability and criterion validity of the International Fitness Scale (IFIS), Portuguese version (IFIS-LP) in Brazilian pediatric populations and the IFIS-LP construct validity to predict high blood pressure in children and adolescents.

\section{Materials and Methods}

We conducted an observational study of reliability and validity. This study used data from a random sample of children aged 3-10 years and adolescents aged 11-17 years [17] who were enrolled in preschool, primary school, and up to the third year of high school at both public and private schools in the city of Teresina, Piauí, Brazil, who participated in the South American Youth/Child Cardiovascular and Environmental (SAYCARE) study [18]. The exclusion criteria were an inability to perform physical tests (pregnancy, use of medications for blood pressure, heart conditions, or joint pain) and/or respond to questionnaires, and/or refusing to sign the informed consent. This consent was necessary for the parents or guardians and for the adolescents or children. In addition, the headmasters of the selected schools also gave their consent to collaborate with the study. Three schools were chosen due to convenience for data collection. Their headmasters were contacted and received a formal 
invitation with detailed information about the study. For the schools that agreed to participate, an information letter and verbal explanation were provided for the potential participants and their parents or guardians.

To assess the reliability of the questionnaire [12] (self-reported physical fitness), measurements were taken from the same subjects on two occasions with a 15-day interval, following international protocols [19]. For children, the parents or guardians filled out the questionnaire [12,20], whereas the adolescents answered the questions by themselves. The criterion validity of the questionnaire was evaluated by comparing it to the physical test (described below). To test the construct validity, we analyzed the questionnaire responses with high blood pressure prevalence. The health indicator chosen was high blood pressure [21], as low levels of physical fitness are associated with the development of cardiovascular diseases [22]. Additionally, systemic arterial hypertension is an independent risk factor for cardiovascular diseases [21]. Maternal education was classified according to years of school, as reported by the questionnaire. The options for maternal education according to years of school were $<4$ years, $4-8$ years, $9-12$ years, or $>12$ years [23].

\subsection{Measures}

\subsubsection{Subjective Measurement Methods (Self-Reported Physical Fitness)}

Self-reported physical fitness was evaluated through the IFIS [12], the International Fitness Scale, in the Portuguese language version (IFIS-LP). The IFIS was originally written in English and then translated and culturally adapted (reverse translation) [24]. After translation permission, the IFIS-LP underwent cross-cultural adaptation for the production of the Portuguese version of the questionnaire, according to the methodology proposed by Herdman [25]. The IFIS contains five items related to general physical fitness, cardiorespiratory fitness, muscular fitness, speed/agility, and flexibility levels, with answers scored on a five-point Likert scale (very poor, poor, average, good, and very good). The questions address an individual's self-perception of physical fitness evaluated against that of his/her friends. In cases of doubt, the research team was able to clarify some of the components of physical fitness. For agreement analysis, the results of the Likert scale responses for the five IFIS-LP questions were dichotomized into good/great (average, good, and very good) and low/very low (poor and very poor) for all bands, according to recommendations in the literature [26].

\subsubsection{Objective Measurement Methods}

\section{Anthropometry}

The anthropometric variables of weight and height were analyzed according to the reference manual of anthropometric standardization of the World Health Organization (WHO) [27]. Body mass index (BMI) was calculated as an individual's body weight in kilograms divided by the square of his/her height in meters [27]. We used an ultra Slim W801 digital scale (Crivitta Diagnostica Ltd, São Paulo, Brazil) and Wall stadiometer (Cardiomed, Paraná, Brazil). Anthropometric variables were measured once and then later repeated. An additional measurement was performed in cases of an error of $5 \%$ between the first and the second measurements. The evaluations were conducted in a private room at the school. All measures were taken in underwear or with as few clothes as possible and without shoes.

\section{Blood Pressure (BP) Measurements}

We measured systolic (SBP) and diastolic (DBP) blood pressure with a calibrated mercury column sphygmomanometer coupled to an Omron device (Omron Health Care, Japan), model HEM-7200, with an appropriate cuff for each arm size. We used three different cuffs according to the following anthropometric measurements of the arm: 12 to $21 \mathrm{~cm}$ (small), 22 to $32 \mathrm{~cm}$ (medium), and 33 to $42 \mathrm{~cm}$ (large) [28]. The measurements were performed on the right arm of the participants because of 
coarctation of the aorta, and the arm was supported at the level of the heart: All were placed in a quiet room. The children and adolescents sat, their backs resting on a chair, a relaxed arm resting on a rigid surface, and uncrossed feet resting on the floor. After 5 min of rest, the measurement was initiated. $\mathrm{BP}$ was determined by averaging two measurements taken within $5 \mathrm{~min}$ of each other, with the subject resting for at least $5 \mathrm{~min}$ before the first measurement [29]. High blood pressure (HBP) was defined as SBP and DBP above the 95th percentile for sex, age, and height following the American Academy of Pediatrics protocol [30].

\section{Physical Fitness Tests}

To ensure objectivity of the measurements of physical fitness, a detailed manual of operations on the field-based fitness tests was read by every researcher involved in the fieldwork before data collection started. In addition, all researchers performed one week of training in order to standardize and harmonize measurement of the physical fitness tests. Physical tests were performed after BP was measured. All physical tests were performed individually, in the following order. Muscular fitness (MF) was assessed using two tests [31]: (1) The handgrip test (maximum handgrip strength assessment) using a hand dynamometer with an adjustable grip (JamarßPC5030J1, Fit Systems Inc., Calgary, Canada). The participant stays in a standard bipedal position with the arms in complete extension holding the dynamometer without touching any part of the body with it. Scores were calculated as the average of the right and left handgrip strength used in the analysis [26]. Two trials were allowed for each hand, and the average score was recorded in kilograms (kg). (2) The standing broad jump test (lower limb explosive strength assessment). The participant jumps as far as possible off the stand, trying to land with both feet together and maintain equilibrium once landed (they were not allowed to put their hands on the floor). The score was obtained by measuring the distance between the last heel mark and the take-off line. The best of two attempts was recorded in centimeters [32]. We computed the MF variable as the average of the two MF tests. Flexibility was measured by the sit-and-reach test for range of movement (in $\mathrm{cm}$ ) [32]. Speed and agility were assessed with the $4 \times 10-\mathrm{m}$ shuttle run test, a test where the participant runs as fast as possible from the starting line to the other line and returns to the starting line (10 m apart), crossing each line with both feet every time. This was performed twice and covered a distance of $40 \mathrm{~m}(4 \mathrm{~m} \times 10 \mathrm{~m})$. Every time the child crossed any of the lines, he/she picked up (the first time) or exchanged a sponge that had been previously placed behind the lines. The time taken to complete the test was recorded to the nearest tenth of a second [32]. Cardiorespiratory fitness (CRF) was assessed by the 20-m shuttle run test [33]. Participants were required to run between two lines $20 \mathrm{~m}$ apart, while keeping pace with audio signals emitted from a prerecorded compact disc. The group of children was evaluated using a modified version of the original test [33], reducing the initial velocity to $6.5 \mathrm{~km} / \mathrm{h}$. For the adolescents, the initial speed was $8.5 \mathrm{~km} / \mathrm{h}$, which was increased by $0.5 \mathrm{~km} / \mathrm{h}(1 \mathrm{~min}=1$ stage $)$ [26]. Participants were encouraged to keep running as long as possible throughout the course of the test, and it was completed when the participants failed to reach the end lines concurrent with the audio signals on two consecutive occasions. The last half-stage completed was recorded as an indicator of his or her CRF. Overall fitness was computed as the average of all four physical fitness components studied [12].

The results of the children's physical tests were used to classify this group according to good/great physical fitness ( $\geq 90$ th percentile for age and sex in this sample) and low/poor physical fitness (below the 90th percentile). Based on a reference for European children, a Likert-type scale to classify children's performance was as follows: (very poor ( $X<$ percentile 10 ), poor (percentile $10 \geq X<$ percentile 25), good (percentile $75 \leq$ percentile 90 ), and very good ( $\geq$ percentile 95$)$ ) [34]. For the adolescent results, we used age- and sex-adjusted cutoffs [2,10,34].

\subsection{Data Collection}

Data collection occurred during five school visits: 
(1) An explanation of the project and the delivery of informed consent to be signed by parents/guardians or the adolescents themselves;

(2) The delivery of the questionnaire (parents or adolescent self-completion) for an evaluation of self-reported physical fitness, blood pressure measurements, and anthropometric measurements;

(3) The collection of the completed questionnaire (self-reported physical fitness) and an objective evaluation of physical fitness (field test);

(4) The second delivery of the questionnaire in order to assess reliability; and

(5) The collection of the completed questionnaire (second application) and a second objective evaluation of physical fitness (field test (we considered the second evaluation for analysis)).

\subsection{Statistical Analysis}

Sample size calculations were performed to verify the reliability and validity of the self-reported physical fitness questionnaire in the study population, for which we used values from the cardiorespiratory fitness physical test [33]. For the reliability analysis, the sample size was calculated by using a nomogram [35], and the parameters used were an alpha $(\alpha)$ of 0.05 (type I error), a beta $(\beta)$ or power (type II error) of 0.80 , and a kappa coefficient $(\kappa)$ of 0.70 . For the validity analysis, the parameters were as follows: an $\alpha$ of 0.05 (type I error) (two-tailed), a $\beta$ or power (type II error) of 0.80 , and a kappa coefficient of 0.80 . From these parameters, the necessary sample size estimated was 135 participants for the reliability analysis and 119 for the validity analysis. Considering the possible loss of participants, a $10 \%$ greater sample size was recruited for these analyses $(n=149$ for reliability and $n=131$ for validity). The descriptive analysis included calculating the mean, the percentage, and their respective $95 \%$ confidence intervals ( $95 \% \mathrm{CI}$ ). The normality of the sample was observed through the Shapiro-Wilk test.

The test-retest reliability of the self-reported physical fitness measurements was calculated for categorical variables by using the kappa statistic. Kappa coefficients $(\kappa \geq 0.40)$ [36] were considered acceptable. To test the validity of the criterion, we analyzed the agreement between the questionnaire and the physical test, and the validity of the construct was calculated by the concordance of the questionnaire between high blood pressure and the kappa coefficient, where moderate (or higher) values of the kappa concordance coefficient $\geq 0.40$ [36] were considered acceptable. It was assumed that good/great physical fitness in the questionnaire would be in agreement with good/great physical fitness in the physical test and with normal pressure (by measuring blood pressure). For a complementary validity analysis and to understand if the questionnaire discriminated between the children and adolescents according to the field test, we applied a Kruskal-Wallis ANOVA to compare the fitness field test results across the questionnaire categories.

We applied a $2 \times 2$ contingency table, and the sensitivity and specificity of the questionnaire were considered: Sensitivity, which was the proportion of participants with good/great physical fitness according to both instruments ((self-reported physical fitness and physical fitness tests)-(proportion of participants with normal blood pressure and good/great physical fitness according to both instruments)); specificity ((proportion of participants with very poor physical fitness, poor according to both instruments)-(proportion of participants with high blood pressure and very poor physical fitness, poor according to both instruments)); prevalence (participants with good/great physical fitness according to the questionnaire); and accuracy (proportion of participants correctly diagnosed by both instruments). Stata software version 14.0 (StataCorp, College Station, Texas) was used for all statistical analyses.

\subsection{Ethical Considerations}

This study was approved by the Research Ethics Committee of the University of São Paulo Medical School, filed under number (58930816.7.0000.0065). Written informed consent was obtained from all of the participants in the study. 


\section{Results}

The sample of this study was composed of a pediatric population aged 3 to 17 years. One-hundred and ninety children and 110 adolescents participated in the study, with a total of 300 participants evaluated. Table 1 shows the descriptive variables. The mean age of the children was 6.7 , and for adolescents, it was 14.6 years.

Table 1. Basic characteristics of the studied children and adolescents.

\begin{tabular}{ccc}
\hline & Children $(\boldsymbol{n}=\mathbf{1 9 0})$ & Adolescents $(\boldsymbol{n = 1 1 0})$ \\
\cline { 2 - 3 } & Mean or \% (SD) & Mean or \% (SD) \\
\hline Age & $6.7(2.1)$ & $14.6(1.8)$ \\
Body weight $(\mathrm{kg})$ & $25.8(11.3)$ & $51.7(11.4)$ \\
Height $(\mathrm{cm})$ & $119.1(15.5)$ & $158.4(12.0)$ \\
BMI $\left(\mathrm{kg} / \mathrm{m}^{2}\right)$ & $17.5(3.4)$ & $20.7(5.6)$ \\
Systolic blood pressure (mmHg) & $95.5(9.9)$ & $109.9(5.3)$ \\
Diastolic blood pressure $(\mathrm{mmHg})^{\text {High blood pressure }(\%)}$ & $64.3(8.4)$ & $65.5(4.0)$ \\
Maternal education level $(\%)$ & 1.9 & 2.9 \\
Incomplete high school & & 23.3 \\
High school & 16.0 & 40.0 \\
Technical education & 21.5 & 6.67 \\
University degree & 8.3 & 30.0 \\
\hline
\end{tabular}

SD: standard deviation; BMI: body mass index. High blood pressure was defined as systolic blood pressure or diastolic blood pressure above the 95 th percentile for sex, age, and height.

Self-reported physical fitness is presented in Table 2. Most parents/guardians of the children rated their children's physical fitness as acceptable or good physical fitness. Most adolescents reported acceptable physical fitness.

Table 2. Distribution of responses by categories of self-reported physical fitness $\left({ }^{*}\right)$ in children and adolescents.

\begin{tabular}{|c|c|c|c|c|c|}
\hline \multirow{2}{*}{ Components } & \multicolumn{5}{|c|}{ Children $(n=190)$} \\
\hline & Very good \% (n) & Good \% (n) & Average \% (n) & Poor \% $(n)$ & Very poor $\%(n)$ \\
\hline Overall fitness & $15.8(30)$ & $26.8(51)$ & $28.4(54)$ & $27.9(53)$ & $1.1(2)$ \\
\hline Cardiorespiratory fitness & $12.1(23)$ & $24.7(47)$ & $31.2(59)$ & $28.9(55)$ & $3.1(6)$ \\
\hline Muscular strength & $18.9(36)$ & $20.0(38)$ & $31.6(60)$ & $25.8(49)$ & $3.7(7)$ \\
\hline Speed and agility & $18.9(36)$ & $33.7(64)$ & $32.6(62)$ & $14.3(27)$ & $0.5(1)$ \\
\hline Flexibility & $8.4(16)$ & $22.1(42)$ & $46.9(89)$ & $20.0(38)$ & $2.6(5)$ \\
\hline \multirow{2}{*}{ Components } & \multicolumn{5}{|c|}{ Adolescents $(n=110)$} \\
\hline & Very good \% (n) & Good \% (n) & Average $\%(n)$ & Poor \% $(n)$ & Very poor $\%(n)$ \\
\hline Overall fitness & $5.5(6)$ & $24.5(27)$ & $62.7(69)$ & $5.5(6)$ & $1.8(2)$ \\
\hline Cardiorespiratory fitness & $9.1(10)$ & $18.2(20)$ & $50.9(56)$ & $15.5(17)$ & $6.3(7)$ \\
\hline Muscular strength & $1.0(1)$ & $30.9(34)$ & $58.2(64)$ & $8.1(9)$ & $1.8(2)$ \\
\hline Speed and agility & $7.3(8)$ & $30.9(34)$ & $53.6(59)$ & $7.3(8)$ & $0.9(1)$ \\
\hline Flexibility & $5.4(6)$ & $20.9(23)$ & $50.0(55)$ & $14.6(16)$ & $9.1(10)$ \\
\hline
\end{tabular}

* IFIS-LP: International Fitness Scale, Portuguese version.

Table 3 shows the test-retest reliability statistics in children and adolescents from Teresina Piauí, Brazil, for the five items that comprise the IFIS, that is, overall fitness and the four main fitness components: CRF, MF, speed and agility, and flexibility. The reliability coefficients were acceptable for all components of physical fitness in the group of children and adolescents. 
Table 3. Test-retest (one week apart) reliability of the physical fitness questionnaire ${ }^{*}$ ) in the pediatric population from Teresina Piauí, Brazil.

\begin{tabular}{ccccc}
\hline \multirow{2}{*}{ Components } & \multicolumn{2}{c}{ Children $(n=\mathbf{1 9 0})$} & \multicolumn{2}{c}{ Adolescents $(n=\mathbf{1 1 0})$} \\
\cline { 2 - 5 } & Agreement \% & $\kappa$ & Agreement \% & $\kappa$ \\
\hline Overall fitness & 99.47 & $\mathbf{0 . 9 9}$ & 96.36 & $\mathbf{0 . 9 3}$ \\
Cardiorespiratory fitness & 98.95 & $\mathbf{0 . 9 8}$ & 99.18 & $\mathbf{0 . 9 7}$ \\
Muscular strength & 96.32 & $\mathbf{0 . 9 5}$ & 96.36 & $\mathbf{0 . 9 3}$ \\
Speed and agility & 98.95 & $\mathbf{0 . 9 8}$ & 92.73 & $\mathbf{0 . 8 8}$ \\
Flexibility & 95.26 & $\mathbf{0 . 9 3}$ & 93.64 & $\mathbf{0 . 9 0}$ \\
\hline
\end{tabular}

* IFIS-LP: International Fitness Scale, Portuguese version, applied at two different times with an interval of 15 days; k: Moderate (or above) kappa concordance coefficient $(\kappa \geq 0.40)$ values are in bold

Table 4 presents the validity of the self-reported physical fitness based on the agreement between the measures of the questionnaire and the physical test (criterion validity). The coefficient of validity showed an acceptable value for all components of physical fitness in both groups of children and adolescents.

Table 4. Criterion of validity of the physical fitness questionnaire $\left(^{*}\right)$ in the pediatric population.

\begin{tabular}{ccccc}
\hline \multirow{2}{*}{ Components } & \multicolumn{2}{c}{ Children $(n=\mathbf{1 9 0})$} & \multicolumn{2}{c}{ Adolescents $(n=\mathbf{1 1 0})$} \\
\cline { 2 - 5 } & Agreement $\%$ & $\boldsymbol{K}$ & Agreement \% & $\boldsymbol{k}$ \\
\hline Overall fitness & 82.63 & $\mathbf{0 . 6 0}$ & 82.73 & $\mathbf{0 . 4 9}$ \\
Cardiorespiratory fitness & 86.26 & $\mathbf{0 . 6 5}$ & 81.82 & $\mathbf{0 . 4 0}$ \\
Muscular strength & 76.26 & $\mathbf{0 . 5 0}$ & 83.84 & $\mathbf{0 . 4 3}$ \\
Speed and agility & 79.47 & $\mathbf{0 . 5 0}$ & 86.36 & $\mathbf{0 . 5 4}$ \\
Flexibility & 70.00 & $\mathbf{0 . 4 0}$ & 84.55 & $\mathbf{0 . 5 3}$ \\
\hline
\end{tabular}

* IFIS-LP: International Fitness Scale, Portuguese version, applied at two different times with an interval of 15 days; $\kappa:$ Moderate (or above) kappa concordance coefficient $(\kappa \geq 0.40)$ values are in bold; criterion validity: Estimated by the agreement between the questionnaire and the physical test.

The sensitivity and specificity of the self-reported physical fitness are shown in Table 5. The questionnaire presented greater sensitivity and lower specificity in the group of children and adolescents when compared to the field tests.

Table 5. Sensitivity and specificity of the physical fitness questionnaire ${ }^{*}$ ) compared to field tests in the pediatric population.

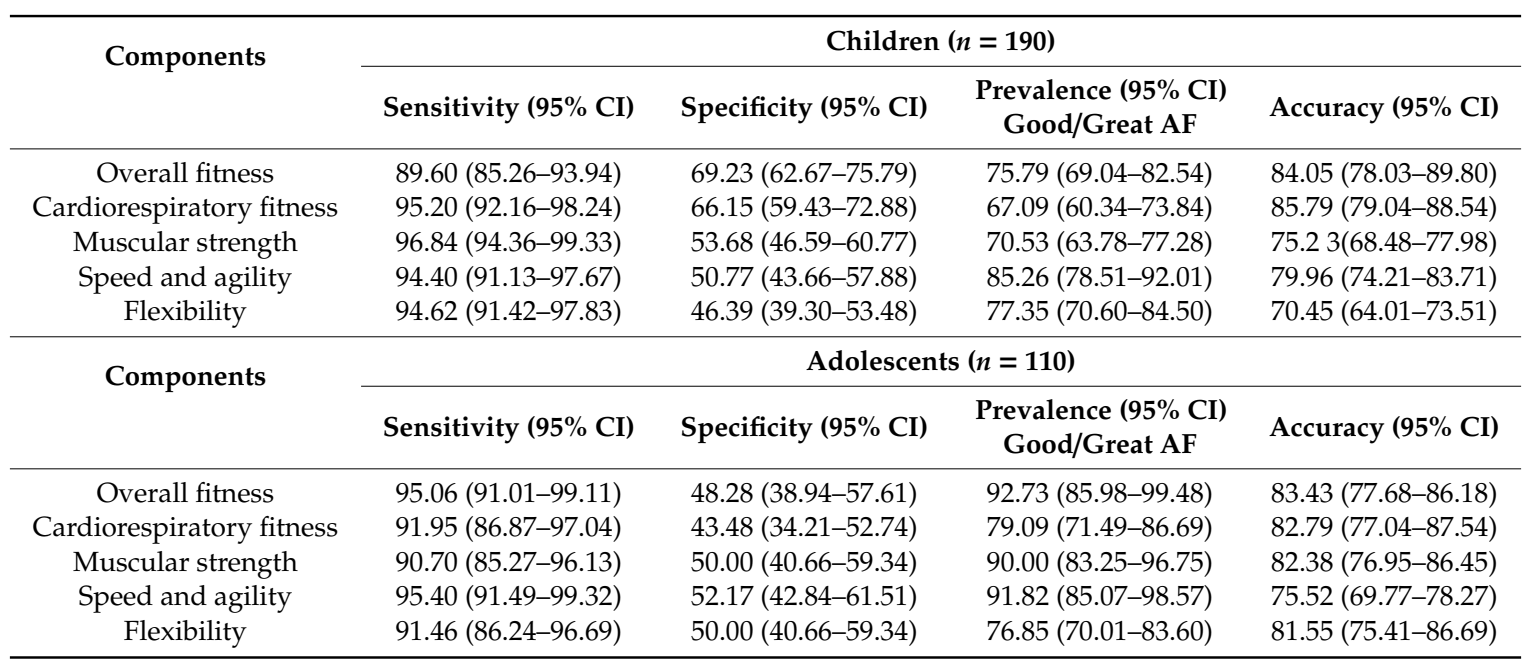

IFIS-LP: International Fitness Scale, Portuguese version; CI: Confidence interval; AF: Physical fitness; sensitivity (proportion of participants with good/great AF in the questionnaire and field test); specificity (proportion of participants with low/poor AF in the questionnaire and field test); accuracy (proportion of participants correctly diagnosed by both methods). 
Table 6 presents the physical fitness field test results according to the physical fitness questionnaire categories in both groups of children and adolescents. Children classified as very good presented higher results in the field tests for all of the fitness components. On the other hand, in adolescents, only for flexibility was the result not significant when we compared the very good to the very poor category.

Table 6. Physical fitness field test results according to the physical fitness questionnaire categories in children and adolescents.

\begin{tabular}{|c|c|c|c|c|c|}
\hline \multirow{2}{*}{ Components } & \multicolumn{5}{|c|}{ Children $(n=190)$} \\
\hline & Very Good & Good & Average & Poor & Very Poor \\
\hline & Median (IQR) & Median (IQR) & Median (IQR) & Median (IQR) & Median (IQR) \\
\hline Cardiorespiratory fitness (mt) & $704(645-880)$ & 755 (658.5-884.5) & $833(696-943)$ & $730(565-857)$ & $661(632-1001)$ \\
\hline Muscular strength $(\mathrm{kg})$ & $11.5(8-13.5)$ & $10(7-13.5)$ & $8(6-12)$ & $6(4-11.5)$ & 7 (5.5-9.5) \\
\hline Speed and agility (seg) & $13.7(13.2-15.2)$ & $14.6(13.2-17)$ & $16.1(13.7-19.7)$ & $16.9(14-19)$ & $17.6(15.2-24.9)$ \\
\hline Flexibility $(\mathrm{cm})$ & $28(24-31)$ & $23(20-29)$ & $24.5(20-28)$ & $25(19-29)$ & $20(18.5-24)$ \\
\hline \multirow{3}{*}{ Components } & \multicolumn{5}{|c|}{ Adolescents $(n=110)$} \\
\hline & Very Good & Good & Average & Poor & Very Poor \\
\hline & Median (IQR) & Median (IQR) & Median (IQR) & Median (IQR) & Median (IQR) \\
\hline Cardiorespiratory fitness (mt) & $665(614-768)$ & $625(574-750)$ & $674.5(616-725.5)$ & $600(555.5-766)$ & $605.5(620-778)$ \\
\hline Muscular strength $(\mathrm{kg})$ & $19(16.5-29)$ & $26.5(21.5-33)$ & $23.5(18-28)$ & $19.8(17-23.5)$ & $14(23-25)$ \\
\hline Speed and agility (seg) & & $12.6(4-14.6)$ & $12.3(4-14.2)$ & $14.1(12.7-15.6)$ & $14.6(14-15)$ \\
\hline Flexibility $(\mathrm{cm})$ & $22(15-30)$ & $20.5(17.5-27)$ & $22(16-26)$ & $18(15-23)$ & $18(7-22)$ \\
\hline
\end{tabular}

SD: Standard deviation; IQR: Interquartile range; * IFIS-LP: International Fitness Scale, Portuguese version. In bold, differences $(p<0.05)$ between the groups.

The construct validity (sensitivity and specificity) of the questionnaire compared to blood pressure is shown in Table 7. The questionnaire presented greater sensitivity and lower specificity in the group of children and adolescents, except in the components of general conditioning and flexibility in the group of children that presented greater specificity. The sensitivity of the questionnaire represented the proportion of individuals who had the outcome "good/great physical fitness", while the specificity of the questionnaire represented the proportion of individuals who did not have that outcome. These values are presented in more detail in Table 7. The means of performance from the physical fitness tests in children and adolescents are shown in the Supplementary Materials, Tables S1 and S2.

Table 7. Physical fitness questionnaire accuracy, sensitivity, and specificity (construct validity) to predict high blood pressure (HBP) in the pediatric population.

\begin{tabular}{cccc}
\hline \multirow{2}{*}{ Fitness Components } & \multicolumn{3}{c}{ Children $(\boldsymbol{n = 1 9 0 )}$} \\
\cline { 2 - 4 } & Sensitivity (95\% CI) & Specificity (95\% CI) & Accuracy (95\% CI) \\
\hline Overall fitness & $79.78(71.66-87.90)$ & $100.00(100.00-100.00)$ & $76.79(75.55-80.40)$ \\
Cardiorespiratory fitness & $93.26(88.19-98.33)$ & $40.00(30.10-49.90)$ & $89.00(86.90-94.40)$ \\
Muscular strength & $88.76(82.38-95.15)$ & $80.00(71.91-88.09)$ & $87.08(82.90-90.30)$ \\
Speed and agility & $88.76(82.38-95.15)$ & $60.00(50.10-69.90)$ & $86.38(81.12-90.70)$ \\
Flexibility & $78.65(70.37-86.94)$ & $100.00(100.00-100.00)$ & $74.16(73.00-80.25)$ \\
\hline Components & & Adolescents $(\boldsymbol{n}=\mathbf{1 1 0})$ & \\
\cline { 2 - 4 } & Sensitivity (95\% CI) & Specificity (95\% CI) & Accuracy (95\% CI) \\
\hline Overall fitness & $81.48(68.02-94.94)$ & $60.00(43.03-76.97)$ & $78.88(65.39-88.57)$ \\
Cardiorespiratory fitness & $85.19(72.88-97.49)$ & $60.00(43.03-76.97)$ & $81.87(68.38-91.53)$ \\
Muscular strength & $77.78(63.37-92.18)$ & $80.00(66.14-93.86)$ & $77.96(62.07-83.59)$ \\
Speed and agility & $88.89(78.00-99.78)$ & $60.00(43.03-76.97)$ & $84.37(71.84-94.05)$ \\
Flexibility & $92.59(83.52-100.00)$ & $40.00(23.03-56.97)$ & $83.66(73.29-93.13)$ \\
\hline
\end{tabular}

* IFIS-LP: International Fitness Scale, Portuguese version; high blood pressure was defined as systolic blood pressure or diastolic blood pressure above the 95th percentile for sex, age, and height; sensitivity (proportion of participants with good/great physical fitness according to the questionnaire and HBP); specificity (proportion of participants with low/poor physical fitness according to the questionnaire and HBP); accuracy (proportion of participants correctly diagnosed through both methods). 


\section{Discussion}

This study was performed to establish the reliability and validity of a physical fitness self-report questionnaire, the IFIS (International Fitness Scale, Portuguese version), in a pediatric population, since the reduction of this aptitude is directly associated with early mortality [37]. The physical fitness questionnaire showed almost perfect reliability coefficients in both age groups. The criterion validity coefficient was acceptable in both the children and adolescents. In children, the questionnaire showed moderate construct validity in the components of general conditioning, cardiorespiratory capacity, muscular strength, and speed/agility. In adolescents, the questionnaire demonstrated moderate construct validity in the components of cardiorespiratory capacity, muscular strength, and speed/agility. The questionnaire was shown to be a sensitive method to measure physical fitness in the pediatric population.

These results indicate that the IFIS questionnaire (Portuguese language version) may be useful for estimating the level of physical fitness in the pediatric population, as it is a powerful tool in epidemiological research since it can be used on a large scale, at low cost, and with easy logistics.

Our results showed that parents/guardians and adolescents understood the IFIS issues. Studies have indicated that younger individuals have greater flexibility [38]. Flexibility tends to decrease with age, which may be related to distinct patterns of routine use of major body joints throughout life [39]. In the group of children, flexibility was classified as one of the physical fitness components with the best performance. These results showed that the parents/guardians of the children understood the questions in the questionnaire and were able to respond to them in a way that was very close to the real one, since they were in agreement with the literature [38,39]. Studies have indicated that the younger the age, the greater the flexibility [38]. Flexibility tends to decline after age 17, partly as a result of a decline in physical activity and normal aging [40]. The same was observed among adolescents, and general physical fitness was indicated as one of the best components in this group. The components of physical fitness are inseparable from fundamental movement skills [41,42]. Rarely, or perhaps never, does the individual perform a movement activity that does not involve some aspect of strength, speed, or flexibility. As adolescents are in a specialized movement phase [43], it is assumed that during physical activity and physical exercise, they realize that their performance is strictly related to the acquisition of all components of physical fitness. This may indicate that parents/guardians and adolescents did not randomly choose between the options in questionnaire responses.

The physical fitness questionnaire showed reliability coefficients of near perfect agreement in the groups of children and adolescents. These results indicate that the questionnaire had an acceptable reliability in measuring physical fitness in the pediatric population. Previous studies performed with children between 9 and 12 years of age, adolescents, and adults have presented lower values of reliability $[12,14,15,44]$. In our study, we evaluated children 3 years of age and older: In this age group, parents and/or guardians closely follow the growth and development [43] of their children. In this sense, by observing them alone and in a group, parents tend to also have a greater knowledge of the children who study with their children.

Another explanation for the reliability of the results of the questionnaire is that people may have a better subjective perception of their strength than when asked about physical activity. The physical activity questionnaire generally covers different domains [45]. Therefore, many questions are needed to investigate the construct of interest, which can lead to errors, overlapping responses, and reduced attention and motivation [46]. On the other hand, in the IFIS-LP, there are only five questions for the construction of five variables [12]. Due to the nature of the very specific IFIS-LP issues, the answers are less likely to overlap or confuse, thus reducing memory bias and increasing the chance of bias of the desired behavior. Most likely, physical fitness questionnaires [47-50] have better results than physical activity questionnaires because it is easier to have a subjective perception of the physical valences required to perform physical effort than to report behaviors related to physical activity [51]. The IFIS was designed with the principle that the human brain may be more accurate in classification than in 
quantification [12], so it is easier to classify people into categories (e.g., normal or overweight) than to estimate their current weight.

We found a moderate validity of the physical fitness questionnaire when compared to the physical test. The findings of the present study indicate that the IFIS-LP questionnaire has an acceptable validity in measuring physical fitness in children and adolescents when compared to physical tests (criterion validity). The performance of the instrument in relation to the physical test can be explained in the literature by the correlation between the evaluated outcomes [32,52]. Recent studies have also indicated an acceptable validity of the physical fitness questionnaire compared to physical tests $[12,14,15]$. Our results indicate that there is a concordance of the criteria measured in the physical fitness questionnaire when compared to the physical tests.

The IFIS questionnaire, as a physical fitness identifier, was verified according to sensitivity parameters (efficiency in identifying the presence of physical fitness) and specificity (efficiency in identifying the absence of physical fitness). Simpler tests can be used as substitutes for more elaborate but more accurate or precise forms of establishing the presence of an outcome and/or disease [53,54]. However, we must consider that there was a risk of error in the classification of these results, for example, rating one with the presence of physical fitness when in fact it was absent. However, this risk was justified by the safety and convenience of simpler tests, such as the questionnaire used in this study. In addition, childhood daily play routines require adequate physical conditioning to perform physical activities [41]. The involvement of adolescents in physical activities can transform the prognosis of this health indicator [55] because the evolution of physical fitness can be perceived during the activities of daily living [3]. Our results indicate that the questionnaire can be used as a screening test.

The agreement between the measurements of physical fitness and high blood pressure supports the construct validity of this questionnaire. Cardiorespiratory fitness is related to high blood pressure [56]. Our results in this study showed that even with a low prevalence of high blood pressure between children and adolescents (Table 1), the results of sensitivity and accuracy were good, since it is more difficult to have good accuracy with a low prevalence [57]. The questionnaire presented high sensitivity, showing good results in assessing people with good/great physical fitness even with a low prevalence of high blood pressure. Cardiorespiratory fitness is a predictor of high blood pressure [56]. Low levels of speed/agility, balance, muscle strength, and cardiorespiratory fitness are significantly related to the onset of high blood pressure [58].

We can highlight some of the strengths of this study. Among them was a comparison between the IFIS physical fitness questionnaire and objective measures (physical tests and blood pressure) in a pediatric population in a middle-income city, with an established, standardized, and poorly explored methodology. Cross-cultural adaptation was performed in order to avoid semantic problems [59], since when the reverse translation was performed, there was agreement among the researchers involved in this evaluation. The validation of instruments requires time, an adequate sample $(n)$, statistical tests, and cultural adaptation procedures [60]. Therefore, this study contributes significantly to the literature in this area of research.

Although the study had strengths, it had limitations that should be discussed. One of the possible limitations of the present study was that the parents who answered the questionnaire in the group of children (3-10 years) may have overestimated the physical fitness of the evaluated ones [12], since the parents self-reported the physical fitness of their children in comparison to the physical fitness of their peers. Another possible limitation was the selection of the sample by convenience and the small prevalence of HBP, which could have been affected by the construct validity. However, since the convenience selection included public and private schools, this type of choice should not have influenced the reliability and validity of the results, since pre-established criteria were used to guarantee presumed socioeconomic representativeness as well as age and sex. The strength of the present study was to evaluate physical fitness through field tests. However, by using the same physical tests used by Ortega et al., these tests can be widely used and tested for validity and reliability [12]. 


\section{Conclusions}

The Portuguese version of the IFIS is a reliable and valid method for estimating physical fitness in pediatric populations. We recommend the use of the IFIS-LP in measuring physical fitness in pediatric populations due to its practicality, low cost, and easy logistics.

Supplementary Materials: The following are available online at http://www.mdpi.com/1010-660X/55/6/286/s1, Table S1: Means of performance by physical fitness tests in children (3 to 10 years). Table S2: Means of performance by physical fitness tests in adolescent (11 to 17 years).

Author Contributions: A.C.F.D.M. contributed to the conception and design of the study, data analysis, interpretation, revision of the manuscript, and approval of the final version of the manuscript; R.C.V.C. provided data collection, data analysis and interpretation, and the writing of the manuscript; H.B.C. and L.T.L. performed manuscript revision and approved the final version of the manuscript.

Funding: Augusto César Ferreira De Moraes was awarded by Young Investigator grant from FAPESP (proc. 2017/20317-0 and 2019/02617-1). Regina received a Ph.D. scholarship from the Brazilian Federal Agency for Support and Evaluation of Graduate Education (CAPES) - Finance Code 001. Francisco Leonardo Torres-Leal received grants from the National Counsel of Technological and Scientific Development (CNPq; proc. 484778/2013-7 and 427893/2016-0). Heráclito B. Carvalho received an advanced scientist scholarship from CNPq (proc. 300951/2015-9). The South American Youth/Child Cardiovascular and Environmental (SAYCARE) study was supported mainly by the Brazilian Government from the National Counsel of Technological and Scientific Development (CNPq; proc. 471266/2013-2) and the Sao Paulo State Government from the Sao Paulo Research Foundation (FAPESP; proc. 2014/11468-6).

Acknowledgments: All authors acknowledge each school's dean/chair, the children, adolescents, and their respective parents for their voluntary participation in the study.

Conflicts of Interest: The authors declare no conflicts of interest.

\section{References}

1. Ortega, F.B.; Ruiz, J.R.; Castillo, M.J.; Sjöström, M. Physical fitness in childhood and adolescence: A powerful marker of health. Int. J. Obes. 2008, 32, 1-11. [CrossRef] [PubMed]

2. Ortega, F.B.; Artero, E.G.; Ruiz, J.R.; España-Romero, V.; Jiménez-Pavón, D.; Vicente-Rodriguez, G.; Moreno, L.A.; Manios, Y.; Béghin, L.; Ottevaere, C.; et al. Physical fitness levels among European adolescents: The HELENA study. Br. J. Sports Med. 2011, 45, 20-29. [CrossRef] [PubMed]

3. Bianco, A.; Jemni, M.; Thomas, E.; Patti, A.; Paoli, A.; Ramos Roque, J.; Palma, A.; Mammina, C.; Tabacchi, G. A systematic review to determine reliability and usefulness of the field-based test batteries for the assessment of physical fitness in adolescents-The ASSO project. Int. J. Occup. Med. Environ. Health 2015, 28, 445-478. [CrossRef] [PubMed]

4. Caspersen, C.J.; Powell, K.E.; Christenson, G.M. Physical activity, exercise, and physical fitness: Definitions and distinctions for health-related research. Public Health Rep. 1985, 100, 126-131. [PubMed]

5. Elbe, A.M.; Wikman, J.M.; Zheng, M.; Larsen, M.N.; Nielsen, G.; Krustrup, P. The importance of cohesion and enjoyment for the fitness improvement of 8-10-year-old children participating in a team and individual sport school-based physical activity intervention. Eur. J. Sport. Sci. 2017, 17, 343-350. [CrossRef] [PubMed]

6. Lee, I.M.; Shiroma, E.J;; Lobelo, F.; Puska, P.; Blair, S.N.; Katzmarzyk, P.T.; Lancet Physical Activity Series Working Group. Effect of physical inactivity on major non-communicable diseases worldwide: An analysis of burden of disease and life expectancy. Lancet 2012, 380, 219-229. [CrossRef]

7. Ortega, F.B.; Silventoinen, K.; Tynelius, P.; Rasmussen, F. Muscular strength in male adolescents and premature death: Cohort study of one million participants. BMJ 2012, 345, e7279. [CrossRef]

8. Andersen, L.B.; Harro, M.; Sardinha, L.B.; Froberg, K.; Brage, S.; Anderssen, S.A. Physical activity and clustered cardiovascular risk in children: A cross-sectional study (the European youth heart study). Lancet 2006, 368, 299-304. [CrossRef]

9. Högström, G.; Nordström, A.; Nordström, P. High aerobic fitness in late adolescence is associated with a reduced risk of myocardial infarction later in life: A nationwide cohort study in men. Eur. Heart J. 2014, 35, 3133-3140. [CrossRef] 
10. Ruiz, J.R.; Espana Romero, V.; Castro Piñero, J.; Artero, E.G.; Ortega, F.B.; Cuenca Garcia, M.; Jiménez Pavón, D.; Chillón, P.; Girela Rejón, M.J.; Mora, J.; et al. Batería ALPHA-Fitness: Test de campo para la evaluación de la condición física relacionada con la salud en niños y adolescentes. Nutr. Hosp. 2011, 26, 1210-1214.

11. Ombrellaro, K.J.; Perumal, N.; Zeiher, J.; Hoebel, J.; Ittermann, T.; Ewert, R.; Dörr, M.; Keil, T.; Mensink, G.B.M.; Finger, J.D. Socioeconomic correlates and determinants of cardiorespiratory fitness in the general adult population: A systematic review and meta-analysis. Sports Med. Open 2018, 4, 25. [CrossRef] [PubMed]

12. Ortega, F.B.; Ruiz, J.R.; España-Romero, V.; Vicente-Rodriguez, G.; Martínez-Gómez, D.; Manios, Y.; Béghin, L.; Molnar, D.; Widhalm, K.; Moreno, L.A.; et al. The International Fitness Scale (IFIS): Usefulness of self-reported fitness in youth. Int. J. Epidemiol. 2011, 40, 701-711. [CrossRef] [PubMed]

13. Álvarez-Gallardo, I.C.; Soriano-Maldonado, A.; Segura-Jiménez, V.; Carbonell-Baeza, A.; Estévez-López, F.; McVeigh, J.G.; Delgado-Fernández, M.; Ortega, F.B. International FItness Scale (IFIS): Construct validity and reliability in women with fibromyalgia: The al-ándalus project. Arch. Phys. Med. Rehabil. 2016, 97, 395-404. [CrossRef] [PubMed]

14. Ramírez-Vélez, R.; Cruz-Salazar, S.M.; Martínez, M.; Cadore, E.L.; Alonso-Martinez, A.M.; Correa-Bautista, J.E.; Izquierdo, M.; Ortega, F.B.; García-Hermoso, A. Construct validity and test-retest reliability of the International Fitness Scale (IFIS) in Colombian children and adolescents aged 9-17.9 years: The FUPRECOL study. Peer J. 2017, 5, e3351. [CrossRef] [PubMed]

15. Sanchez-Lopez, M.; Martinez-Vizcaino, V.; Garcia-Hermoso, A.; Jimenez-Pavon, D.; Ortega, F.B. Construct validity and test-retest reliability of the International Fitness Scale (IFIS) in Spanish children aged 9-12 years. Scand. J. Med. Sci. Sports 2015, 25, 543-551. [CrossRef]

16. Chung, J.W.; Chung, L.M.; Chen, B. The impact of lifestyle on the physical fitness of primary school children. J. Clin. Nurs. 2009, 18, 1002-1009. [CrossRef]

17. World Health Organization. Core Competencies in Adolescent Health and Development for Primary Care Providers; Geneva SWHO: Geneva, Switzerland, 2015; Volume 58.

18. Carvalho, H.B.; Moreno, L.A.; Silva, A.M.; Berg, G.; Estrada-Restrepo, A.; González-Zapata, L.I.; De Miguel-Etayo, P.; Delgado, C.A.; Bove, M.I.; de Sousa, M.D.L.R.; et al. Design and objectives of the south american youth/child cardiovascular and environmental (SAYCARE) study. Obesity 2018, 26, S5-S13. [CrossRef]

19. Marx, R.G.; Menezes, A.; Horovitz, L.; Jones, E.C.; Warren, R.F. A comparison of two time intervals for test-retest reliability of health status instruments. J. Clin. Epidemiol. 2003, 56, 730-735. [CrossRef]

20. Moreno, L.A.; De Henauw, S.; González-Gross, M.; Kersting, M.; Molnár, D.; Gottrand, F.; Barrios, L.; Sjöström, M.; Manios, Y.; Gilbert, C.C.; et al. Design and implementation of the healthy lifestyle in Europe by nutrition in adolescence cross-sectional study. Int. J. Obes. 2008, 32, S4-S11. [CrossRef]

21. Gando, Y.; Sawada, S.S.; Kawakami, R.; Momma, H.; Shimada, K.; Fukunaka, Y.; Okamoto, T.; Tsukamoto, K.; Miyachi, M.; Lee, I.M.; et al. Combined association of cardiorespiratory fitness and family history of hypertension on the incidence of hypertension: A long-term cohort study of Japanese males. Hyperten. Res. 2018, 41, 1063-1069. [CrossRef]

22. Ruiz,J.R.; Cavero-Redondo, I.; Ortega, F.B.; Welk, G.J.; Andersen, L.B.; Martinez-Vizcaino, V.Cardiorespiratory fitness cut points to avoid cardiovascular disease risk in children and adolescents; what level of fitness should raise a red flag? A systematic review and meta-analysis. Br. J. Sports Med. 2016, 50, 1451-1458. [CrossRef] [PubMed]

23. De Moraes, A.C.F.; Forkert, E.C.O.; Vilanova-Campelo, R.C.; González-Zapata, L.I.; Azzaretti, L.; Iguacel, I.; Huicho, L.; Moliterno, P.; Moreno, L.A.; Carvalho, H.B. Measuring socioeconomic status and environmental factors in the SAYCARE study in South America: Reliability of the methods. Obesity 2018, 26, S14-S22. [CrossRef] [PubMed]

24. Marcela, G.-G.; Henauw, S.D.; Gottrand, F.; Gilbert, C.; Moreno, L. Manual of Operation the HELENA Study; Prensas e la Universidd de Zaragoza: Zaragoza, Spain, 2013; p. 289.

25. Herdman, M.; Fox-Rushby, J.; Badia, X. A model of equivalence in the cultural adaptation of HRQoL instruments: The universalist approach. Qual. Life Res. 1998, 7, 323-335. [CrossRef] [PubMed]

26. Cadenas-Sanchez, C.; Martinez-Tellez, B.; Sanchez-Delgado, G.; Mora-Gonzalez, J.; Castro-Piñero, J.; Löf, M.; Ortega, F.B. Assessing physical fitness in preschool children: Feasibility, reliability and practical recommendations for the PREFIT battery. J. Sci. Med. Sport. 2016, 19, 910-915. [CrossRef] [PubMed] 
27. World Health Organization. Physical Status: The Use and Interpretation of Anthropometry; Report of a WHO Expert Committee; Technical Report Series; World Health Organization: Geneva, Switzerland, 1995; Volume 854, pp. 1-452.

28. National High Blood Pressure Education Program Working Group on High Blood Pressure in Children and Adolescents. The fourth report on the diagnosis, evaluation, and treatment of high blood pressure in children and adolescents. Pediatrics 2004, 114, 555-576. [CrossRef]

29. Araújo-Moura, K.; De Moraes, A.C.F.; Forkert, E.C.O.; Berg, G.; Cucato, G.G.; Forjaz, C.L.M.; Moliterno, P.; Gaitan-Charry, D.; Delgado, C.A.; González-Gil, E.M.; et al. Is the measurement of blood pressure by automatic monitor in the South American pediatric population accurate? SAYCARE study. Obesity 2018, 26, S41-S46. [CrossRef] [PubMed]

30. Pickering, T.G.; Hall, J.E.; Appel, L.J.; Falkner, B.E.; Graves, J.; Hill, M.N.; Jones, D.W.; Kurtz, T.; Sheps, S.G.; Roccella, E.J.; et al. Recommendations for blood pressure measurement in humans and experimental animals: Part 1: Blood pressure measurement in humans: A statement for professionals from the subcommittee of professional and public education of the American Heart Association Council on high blood pressure research. Hypertension 2005, 45, 142-161. [PubMed]

31. Ruiz, J.R.; España-Romero, V.; Ortega, F.B.; Sjöström, M.; Castillo, M.J.; Gutierrez, A. Hand span influences optimal grip span in male and female teenagers. J. Hand Surg. Am. 2006, 31, 1367-1372. [CrossRef] [PubMed]

32. Ortega, F.B.; Artero, E.G.; Ruiz, J.R.; Vicente-Rodriguez, G.; Bergman, P.; Hagströmer, M.; Ottevaere, C.; Nagy, E.; Konsta, O.; Rey-López, J.P.; et al. Reliability of health-related physical fitness tests in European adolescents. The HELENA Study. Int. J. Obes. 2008, 32, S49-S57. [CrossRef]

33. Léger, L.A.; Mercier, D.; Gadoury, C.; Lambert, J. The multistage 20 metre shuttle run test for aerobic fitness. J. Sports Sci. 1988, 6, 93-101. [CrossRef]

34. De Miguel-Etayo, P.; Gracia-Marco, L.; Ortega, F.B.; Intemann, T.; Foraita, R.; Lissner, L.; Oja, L.; Barba, G.; Michels, N.; Tornaritis, M.; et al. Physical fitness reference standards in European children: The IDEFICS study. Int. J. Obes. 2014, 38, S57-S66. [CrossRef] [PubMed]

35. Hong, H.; Choi, Y.; Hahn, S.; Park, S.K.; Park, B.J. Nomogram for sample size calculation on a straightforward basis for the kappa statistic. Ann. Epidemiol. 2014, 24, 673-680. [CrossRef] [PubMed]

36. Landis, J.R.; Koch, G.G. The measurement of observer agreement for categorical data. Biometrics 1977, 33, 159-174. [CrossRef] [PubMed]

37. Kodama, S.; Saito, K.; Tanaka, S.; Maki, M.; Yachi, Y.; Asumi, M.; Sugawara, A.; Totsuka, K.; Shimano, H.; Ohashi, Y.; et al. Cardiorespiratory fitness as a quantitative predictor of all-cause mortality and cardiovascular events in healthy men and women: A meta-analysis. JAMA 2009, 301, 2024-2035. [CrossRef] [PubMed]

38. Lamari, N.M.; Chueire, A.G.; Cordeiro, J.A. Analysis of joint mobility patterns among preschool children. Sao Paulo Med. J. 2005, 123, 119-123. [CrossRef] [PubMed]

39. Medeiros, H.B.; de Araújo, D.S.; de Araújo, C.G. Age-related mobility loss is joint-specific: An analysis from 6,000 Flexitest results. Age 2013, 35, 2399-2407. [CrossRef]

40. Committee on Physical Activity and Physical Education in the School Environment. Food and Nutrition Board; Institute of Medicine; Kohl, H.W., III, Cook, H.D., Eds.; National Academies Press: Washington, DC, USA, 2013.

41. Robinson, L.E.; Stodden, D.F.; Barnett, L.M.; Lopes, V.P.; Logan, S.W.; Rodrigues, L.P.; D’Hondt, E. Motor competence and its effect on positive developmental trajectories of health. Sports Med. 2015, 45, 1273-1284. [CrossRef]

42. Cattuzzo, M.T.; dos Santos Henrique, R.; Ré, A.H.; de Oliveira, I.S.; Melo, B.M.; de Sousa Moura, M.; de Araújo, R.C.; Stodden, D. Motor competence and health related physical fitness in youth: A systematic review. J. Sci. Med. Sport 2016, 19, 123-129. [CrossRef]

43. Gallahue, D.L.; Ozmun, J.C.; Goodway, D.J. Compreendendo o Desenvolvimento Motor: Bebês, Crianças, Adolescentes e Adultos, 7th ed.; AMGH Artmed: Porto Alegre, Brasil, 2013; p. 487. ISBN 978-85-8055-180-8.

44. Español-Moya, M.N.; Ramírez-Vélez, R. Psychometric validation of the International FItness Scale (IFIS) in Colombian youth. Rev. Esp. Salud Publica 2014, 88, 271-278. [CrossRef]

45. Nascimento-Ferreira, M.V.; de Moraes, A.C.F.; Toazza Oliveira, P.V.; Rendo-Urteaga, T.; Gracia-Marco, L.; Forjaz, C.L.M.; Moreno, L.A.; Carvalho, H.B. Assessment of physical activity intensity and duration in the paediatric population: Evidence to support an a priori hypothesis and sample size in the agreement between subjective and objective methods. Obes. Rev. 2018, 19, 810-824. [CrossRef] 
46. Kelly, P.; Fitzsimons, C.; Baker, G. Should we reframe how we think about physical activity and sedentary behaviour measurement? Validity and reliability reconsidered. Int. J. Behav. Nutr. Phys. Act. 2016, 13, 32. [CrossRef] [PubMed]

47. Chinapaw, M.J.; Mokkink, L.B.; van Poppel, M.N.; van Mechelen, W.; Terwee, C.B. Physical activity questionnaires for youth: A systematic review of measurement properties. Sports Med. 2010, 40, 539-563. [CrossRef] [PubMed]

48. Nascimento-Ferreira, M.V.; de Moraes, A.C.F.; Toazza-Oliveira, P.V.; Forjaz, C.L.M.; Aristizabal, J.C.; Santaliesra-Pasías, A.M.; Lepera, C.; Nascimento-Junior, W.V.; Skapino, E.; Delgado, C.A.; et al. Reliability and Validity of a Questionnaire for Physical Activity Assessment in South American Children and Adolescents: The SAYCARE Study. Obesity 2018, 26, S23-S30. [CrossRef] [PubMed]

49. Scott, J.J.; Morgan, P.J.; Plotnikoff, R.C.; Lubans, D.R. Reliability and validity of a single-item physical activity measure for adolescents. J. Paediatr. Child. Health 2015, 51, 787-793. [CrossRef] [PubMed]

50. Zaragoza Casterad, J.; Generelo, E.; Aznar, S.; Abarca-Sos, A.; Julián, J.A.; Mota, J. Validation of a short physical activity recall questionnaire completed by Spanish adolescents. Eur. J. Sport Sci. 2012, 12, $283-291$. [CrossRef]

51. Verbestel, V.; de Henauw, S.; Bammann, K.; Barba, G.; Hadjigeorgiou, C.; Eiben, G.; Konstabel, K.; Kovács, E.; Pitsiladis, Y.; Reisch, L.; et al. Are context-specific measures of parental-reported physical activity and sedentary behaviour associated with accelerometer data in 2-9-year-old European children? Public Health Nutr. 2015, 18, 860-868. [CrossRef] [PubMed]

52. Artero, E.G.; España-Romero, V.; Castro-Piñero, J.; Ortega, F.B.; Suni, J.; Castillo-Garzon, M.J.; Ruiz, J.R. Reliability of field-based fitness tests in youth. Int. J. Sports Med. 2011, 32, 159-169. [CrossRef] [PubMed]

53. Fletcher, R.H.; Fletcher, S.W.; Fletcher, G. Epidemiologia Clinica: Elementos Essenciais, 5th ed.; Artmed: Porto Alegre, Brasil, 2014; p. 280. ISBN 978-85-8271-067-8.

54. Szklo, M.; Javier, F.N. Epidemiology: Beyond the Basics, 4th ed.; Burlington: Middlesex, MA, USA, 2018 ; p. 515. ISBN 978-4496-0469-1.

55. Poitras, V.J.; Gray, C.E.; Borghese, M.M.; Carson, V.; Chaput, J.P.; Janssen, I.; Katzmarzyk, P.T.; Pate, R.R.; Connor Gorber, S.; Kho, M.E.; et al. Systematic review of the relationships between objectively measured physical activity and health indicators in school-aged children and youth. Appl. Physiol. Nutr. Metab. 2016, 41, S197-S239. [CrossRef]

56. Klasson-Heggebø, L.; Andersen, L.B.; Wennlöf, A.H.; Sardinha, L.B.; Harro, M.; Froberg, K.; Anderssen, S.A. Graded associations between cardiorespiratory fitness, fatness, and blood pressure in children and adolescents. Br. J. Sports Med. 2006, 40, 25-29. [CrossRef]

57. Swets, J.A. Measuring the accuracy of diagnostic systems. Science 1988, 240, 1285-1293. [CrossRef]

58. Shea, S.; Basch, C.E.; Gutin, B.; Stein, A.D.; Contento, I.R.; Irigoyen, M.; Zybert, P. The rate of increase in blood pressure in children 5 years of age is related to changes in aerobic fitness and body mass index. Pediatrics 1994, 94 Pt 1, 465-470.

59. Reichenheim, M.E.; Moraes, C.L. Operationalizing the cross-cultural adaptation of epidemiological measurement instruments. Rev. Saude Publica 2007, 41, 665-673. [CrossRef] [PubMed]

60. Salmond, S.S. Evaluating the reliability and validity of measurement instruments. Orthop. Nurs. 2008, 27, 28-30. [CrossRef] [PubMed]

(C) 2019 by the authors. Licensee MDPI, Basel, Switzerland. This article is an open access article distributed under the terms and conditions of the Creative Commons Attribution (CC BY) license (http://creativecommons.org/licenses/by/4.0/). 